\title{
(Des)continuidade nos estudos de alunos com deficiência na trajetória do Ensino Fundamental ao Médio: uma análise inicial dos microdados MEC/INEP
}

Laura Ceretta Moreira* Ana Paula de Carvalho**

\section{Resumo}

Este estudo visa colaborar com as discussões das políticas públicas de educação especial, principalmente, no que tange ao alunado com deficiência, matriculado no ensino médio. Para tanto, discorreu-se sobre as conquistas legais que denotam a garantia e obrigatoriedade dessa etapa de ensino na educação básica, bem como suas vicissitudes no contexto da inclusão educacional. Na sequência, a partir apreciação dos Microdados do Censo Escolar, que considera o número total de matrículas e, especificamente, do alunado com deficiência, apresentaram-se os cinco grupos que foram organizados para a análise de dados referentes aos anos: 2007, 2008 e 2010. Sendo que, optou-se por contabilizar as matrículas dos alunos com: cegueira, baixa visão, surdez, deficiência auditiva, surdocegueira, deficiência física, deficiência mental, síndrome de Down e deficiência múltipla (terminologia usada pelo MEC/Inep). Concluiu-se que houve, marcadamente, maior queda nas matrículas de alunos com deficiência em relação ao total de matrículas efetivadas na educação básica, desvelando, o quanto o acesso e a permanência, desse alunado, no ensino médio, última etapa da educação básica, ainda são negligenciados e carecem de pesquisas, avaliação e acompanhamento. A descontinuidade de estudos desta parcela da população demonstra que ainda estamos distantes da garantia do direito à educação a todos, e que o engajamento estatal é fundamental para que isso ocorra.

Palavras-chave: Ensino Médio; Aunos com deficiência; Microdados MEC/Inep.

\footnotetext{
* Professora Doutora da Universidade Federal do Paraná. Curitiba, Parná, Brasil.
}

** Professora da Rede Municipal de Ensino de Curitiba. Curitiba, Paraná, Brasil. 


\title{
(Dis)continuity in studies of students with disabilities in the path of elementary education to high school: an initial analysis of microdata MEC/INEP
}

\begin{abstract}
This study aims to contribute to discussions of public policy for special education, especially in regard to pupils with disabilities enrolled in high school. Therefore, it was spoken out about the legal achievements denoting the warranty and obligation of this step teaching in basic education and its vicissitudes in the context of educational inclusion. Following the assessment of microdata from the School Census, which considers the total enrollment, and specifically of the students with disabilities, presented the five groups that were organized for the analysis of data for the years 2007, 2008 and 2010. Being that it was decided to record enrollment of students with: blindness, low vision, deafness, hearing impairment, deafblindness, physical disability, mental disability, Down syndrome and multiple disabilities (terminology used by MEC / Inep). It was concluded that there was markedly greater decrease in enrollment of students with disabilities in relation to total enrollments in basic education, revealing how much access and retention of these students in high school, the last step of basic education, are still neglected and lack of research, evaluation and monitoring. The discontinuation of study of this portion of the population reveals that we are still far from ensuring the right to education for all and state that the state-owned engagement is essential for this to occur.
\end{abstract}

Keywords: School; Students with disabilities; Microdata MEC/Inep.

\section{Introdução}

Este estudo possui como foco central a análise dos Microdados do Ministério da Educação (MEC)/ Instituto Nacional de Estudos e Pesquisas Educacionais Anísio Teixeira (Inep), apontando como estão ocorrendo o acesso e a permanência dos alunos com deficiência na trajetória do ensino fundamental ao médio, em âmbito nacional. Para tanto, discorreu acerca da trajetória legal que garante a obrigatoriedade dessa etapa de ensino na educação básica, bem como sua complexidade no contexto da inclusão educacional.

Vale ressaltar a escassez de estudos que se remetem aos alunos com deficiência matriculados, no ensino médio, destacam-se as pesquisas de Dias (2004), Cavalcanti (2007), Sudré (2007), Barros (2008), Moreira e Tavares (2008), Cruz (2011) e Carvalho (2012). Essa escassez de pesquisas, de certa forma, aponta para a invisibilidade desse alunado, sobretudo na etapa final da educação básica e, pode retratar, não só o quadro de exclusão educacional desses alunos, mas a precariedade de políticas educacionais que contemplem estratégias de acesso e a permanência para a totalidade da educação básica. 
Moreira e Tavares (2008) já chamavam atenção para esses aspectos ao observarem que os dados do Censo Escolar, MEC/ Inep (2006) indicavam que a matrícula de alunos com necessidades educacionais especiais (NEE), na educação básica, era de 337.326, em 1998, e que evoluiu para 700.624, em 2006, expressando, portanto, um crescimento de $107 \%$. Neste contexto, 112.988 alunos (16\%) frequentavam a educação infantil; 466.155 (66,5\%), o ensino fundamental; 14.150 (2\%), o ensino médio; 58.420 (8,3\%), a educação de jovens e adultos; 46.949 (6,7\%), a educação profissional (básico) e 1.962 (0,28\%) estavam matriculados na educação profissional (técnico). As autoras apontaram o inexpressivo percentual de alunos com NEE que concluíam o ensino fundamental e frequentavam o ensino médio, indicando que essa realidade representava de um lado um quadro de usurpação ao princípio de acesso a essa etapa de ensino e de outro revelava a dupla exclusão de uma etapa da educação básica e de uma modalidade escolar que historicamente mantiveram-se à margem das políticas públicas educacionais.

Dentre as razões do precário acesso ao ensino médio no Brasil está a universalização tardia do ensino fundamental no Brasil. Basta evidenciar que é apenas em 2009, por meio da aprovação da Emenda Constitucional (EC) nº 59, que garantiu a obrigatoriedade da educação básica, que essa temática passa a fazer parte da agenda pública. No art. 6 dessa EC consta que o disposto deverá ser implementado, progressivamente, até 2016. Pinto e Alves (2011), ao apresentarem um estudo sobre o impacto da $E C n^{\circ}$ 59, elucidaram que os "[...] esforços devem ser maiores nas etapas e idades que estavam fora da faixa etária do ensino obrigatório anterior e, por isso, o esforço da educação infantil será maior $(34,4 \%)$, seguido pelo ensino médio $(18,9 \%)$ e do ensino fundamental (2,6\%)" (PINTO; ALVES, 2011, p. 613).

O ensino médio se mostra ainda mais aquém da universalização, quando se trata do número de alunos com deficiência matriculados nessa etapa de ensino. De acordo com o Censo Demográfico (IBGE, 2010), características gerais da população, o número de pessoas com "pelo menos uma das deficiências" registrado, com idade escolar para cursar o ensino médio (15 a 17 anos), chegou a 1.218.607, contingente que representava $11,76 \%$ da população total nessa idade (10.353.865). Já, de acordo com a Consulta de Matrículas do MEC/ Inep, em 2010, havia 8.366.920 alunos nessa etapa de ensino, o número de alunos da educação especial, nessa mesma etapa, era de 34.065 alunos, dessa maneira, 0,40\% dos alunos do ensino médio faziam parte do contingente de alunos da educação especial.

Nesse sentido, constatou-se que há um baixo número de alunos com deficiência matriculados no ensino médio. Pois, enquanto, no Censo Demográfico 2010, consta que $11,76 \%$ da população com idade escolar para cursar o ensino médio apresenta alguma deficiência, os dados do MEC/ Inep, coletados no mesmo ano, evidenciam que somente $0,40 \%$ dos alunos matriculados nesta etapa de ensino apresentavam algum tipo de deficiência.

Esses dados, em certa medida, carecem de credibilidade, até porque não se explicitou adequadamente a metodologia de coleta dos mesmos. Também, é preciso considerar que as categorias de deficiência, elencadas pelo Censo Demográfico, foram 
bastante abrangentes e diferenciaram-se das categorias elencadas pelo Censo Escolar. Contudo, é possível inferir que um grande número de alunos com deficiência tem seu direito de frequentar a última etapa da educação básica negligenciado. Mesmo que, $\mathrm{o}$ atendimento às pessoas com deficiência "[...] preferencialmente na rede regular de ensino" (BRASIL, 1988), tenha sido garantido como direito constitucional há 25 anos.

Diante do contexto exposto, a seguir será apresentada como está se dando a (des)continuidade nos estudos dos alunos com/sem deficiência, na trajetória do ensino fundamental ao médio.

\section{Apreciação dos Microdados do Censo Escolar realizado pelo MEC/Inep: (des)continuidade nos estudos na trajetória do ensino fundamental ao médio}

Com a intenção de discorrer como está se dando a (des)continuidade nos estudos na trajetória do ensino fundamental ao médio e os períodos de evasão acentuada, será realizada, a seguir, uma apreciação dos Microdados do Censo Escolar que considera o número total de matrículas e, especificamente, do alunado com deficiência.

Para extrair os Microdados disponibilizados pelo MEC/ Inep, foi necessário usar a ferramenta $s p s s^{2}$, neste caso utilizou-se a versão estudante que é livre para download. Esta ferramenta tem linguagem própria que é semelhante à linguagem C, assim, através da lógica, utilizou-se os filtros para gerar os agrupamentos de dados que foram restringidos conforme a necessidade deste trabalho.

Nos argumentos de filtros, optou-se por contabilizar as matrículas dos alunos com: cegueira, baixa visão, surdez, deficiência auditiva, surdocegueira, deficiência física, deficiência mental, síndrome de Down e deficiência múltipla (terminologia usada pelo MEC/ Inep). Não foram contabilizadas as matrículas dos alunos com "transtornos invasivos do desenvolvimento" e altas habilidades/ superdotação. Os dados extraídos são referentes aos anos 2007, 2008 e 2010, por série, conforme a necessidade para a formulação dos grupos comparativos ${ }^{3}$ de dados expostos a seguir:

Quadro 1 - Apresentação dos Grupos de análise dos dados MEC/ Inep por período.

\begin{tabular}{|c|c|c|c|}
\hline & 2007 & 2008 & 2010 \\
\hline Grupo 1 & $\begin{array}{c}1^{\underline{a}} \text { série/ } 2^{\underline{Q}} \text { ano do ensi- } \\
\text { no fundamental }{ }^{4}\end{array}$ & & $\begin{array}{l}4^{\mathrm{a}} \text { série/ } 5^{\underline{\mathrm{o}}} \text { ano do } \\
\text { ensino fundamental }\end{array}$ \\
\hline Grupo 2 & $\begin{array}{l}4^{a \underline{a}} \text { série/ } / 5^{\underline{0}} \text { ano do } \\
\text { ensino fundamental }\end{array}$ & $\begin{array}{l}5^{\mathrm{a}} \text { série/ } 6^{\mathrm{o}} \text { ano do } \\
\text { ensino fundamental }\end{array}$ & \\
\hline Grupo 3 & $\begin{array}{l}5^{\mathrm{a}} \text { série/ } 6^{0} \text { ano do } \\
\text { ensino fundamental }\end{array}$ & & $\begin{array}{l}8^{\underline{a}} \text { série/ } 9^{0} \text { ano do } \\
\text { ensino fundamental }\end{array}$ \\
\hline Grupo 4 & $\begin{array}{l}8^{\underline{a}} \text { série/ } 9^{0} \text { ano do } \\
\text { ensino fundamental }\end{array}$ & $1^{o}$ ano do ensino médio & \\
\hline Grupo 5 & & $\mathrm{l}^{\mathrm{o}}$ ano do ensino médio & $3^{0}$ ano do ensino médio \\
\hline
\end{tabular}

Elucida-se que, em princípio, a intenção era realizar uma série histórica, mas, os dados disponibilizados pelo MEC/ Inep não contam com a mesma disposição em períodos anteriores a 2007, razão pela qual, nem todos os anos puderam ser analisa- 
dos na íntegra com relação ao período escolar. Foi, também, a partir de 2007, que o aluno passou a ser unidade básica de coleta no Censo do MEC/ Inep e os dados passaram a ter critérios mais rígidos (BRASIL, 2007).

Com relação aos cinco grupos comparativos neste estudo, elucida-se que no Grupo 1, comparou-se o número total de matrículas e de alunos com deficiência efetivadas na $1^{\underline{a}}$ série/ $2^{\underline{0}}$ ano do ensino fundamental, em 2007, com o número de matrículas total e de alunos com deficiência, realizadas na $4^{\underline{a}}$ série/ $5^{\underline{0}}$ ano do ensino fundamental, em 2010. Dessa forma, foi possível averiguar se os alunos que ingressaram na $1^{\underline{a}}$ série/ $2^{\underline{o}}$ ano do ensino fundamental, em 2007, conseguiram chegar a $4^{\underline{a}}$ série/ $5^{\underline{0}}$ ano no tempo adequado (2010).

No Grupo 2, a fim de visualizar a cobertura para o acesso à segunda etapa do ensino fundamental, o número de matrículas total e de alunos com deficiência realizadas na $4^{\underline{a}}$ série/ $5^{\underline{0}}$ ano, em 2007 , foi confrontado com o de matrículas efetivadas na $5^{a}$ série/ $6^{0}$ ano, em 2008.

No Grupo 3, para indagar a permanência na segunda etapa do ensino fundamental, realizou-se uma comparação entre o número total de matrículas e de alunos com deficiência efetivadas na $5^{\underline{a}}$ série/ $6^{\underline{0}}$ ano do ensino fundamental, em 2007, com o número total de matrículas e de alunos com deficiência realizadas na 8aㅗ série/ 9oano, em 2010.

No Grupo 4, buscando apresentar a cobertura para o acesso ao ensino médio, foram expostas as matrículas totais e de alunos com deficiência efetivadas na 8ª série/ $9^{\circ}$ ano, em 2007, e as matrículas totais e de alunos com deficiência realizadas no $1^{\mathfrak{O}}$ ano do ensino médio, em 2008.

No Grupo 5, comparou-se o número de matrículas total e de alunos com deficiência realizadas no $1^{\circ}$ ano do ensino médio, em 2008, com as matrículas efetivadas no $3^{0}$ ano do ensino médio, em 2010, verificando-se, dessa forma, a continuidade nos estudos nessa etapa de ensino.

É importante observar que as matrículas registradas, no final de cada período, não consideram somente a demanda que havia sido contabilizada no início dos períodos em análise, contemplando, também, matrículas de alunos que haviam evadido ou sido retidos. Mesmo com essas ressalvas, ainda, entende-se que a análise por período pode ilustrar os nichos de (des)continuidade nos estudos do ensino fundamental ao médio.

Sobre a configuração dos dados apresentados em gráficos, esclarece-se que as matrículas foram subdividas por esfera administrativa, considerando-se as redes: federal, estadual, municipal e privada. Contudo, quando as esferas administrativas abrangiam menos de 5\% das matrículas, as mesmas foram desconsideradas. É importante observar que a unidade básica do eixo dos gráficos que apresentam o total de matrículas é sempre 50 vezes maior que o eixo dos gráficos que apresentam o número de matrículas de alunos com deficiência. Com os dados levantados por esfera administrativa, no Grupo 1, foi possível produzir os seguintes dados: 
Gráfico l - Brasil: total de matrículas na $1^{\underline{a}}$ série/ $2^{\underline{0}}$ ano do Ensino Fundamental (2007) e na $4^{4^{a}}$ série/ $5^{\circ}$ ano do Ensino Fundamental (2010)

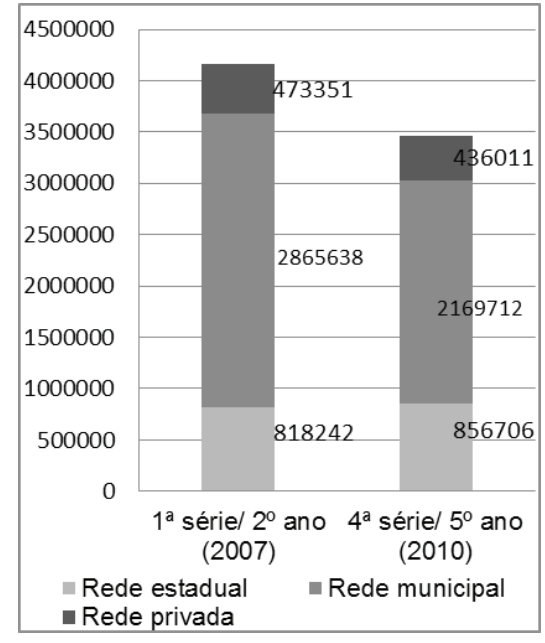

Gráfico 2 - Brasil: matrículas de alunos com deficiência na la série/ $2^{\underline{0}}$ ano do ensino fundamental (2007) e na $4^{\underline{a}}$ série/ $5^{\circ}$ ano do ensino fundamental (2010).

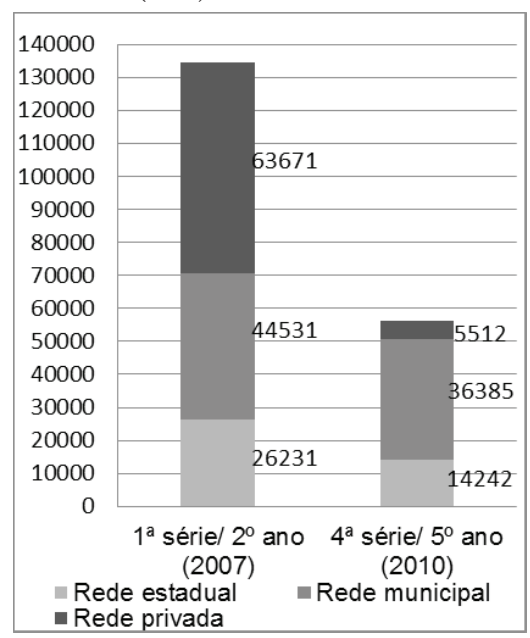

Ambos os gráficos, no período analisado (2007-2010), apresentam redução no número de matrículas. O total de matrículas ${ }^{5}$ sofreu uma queda de $16,69 \%$, já as matrículas de alunos com deficiência tiveram um declive 58,22\%. Assim, o declive é mais que três vezes maior quando se trata o número de matrículas de alunos com deficiência.

Ao observar os dados por dependência administrativa, percebe-se que o número total de alunos matriculados, na rede estadual, aumentou $4,70 \%$. Ao se consi- 
derar as matrículas dos alunos com deficiência, essa rede sofreu queda acentuada de $45,70 \%$

No âmbito municipal, foi ilustrada uma queda de $24,28 \%$ nas matrículas totais e de 18,29\% nas matrículas de alunos com deficiência.

A perda do número de matrículas de alunos com deficiência no setor privado foi exorbitante, chegando a 91,34\%. Quando se considera o número total de matrículas essa inclinação foi menor, visto que foi de 7,88\%. É interessante notar que a rede privada que atende ao alunado com deficiência conta com um número alto de instituições denominadas sem fins lucrativos.

Assim, os dados revelaram que além da redução de matrículas ser mais perversa, quando se trata dos alunos com deficiência $(81,11 \%)$, do que quando se remete às matrículas totais $(58,22 \%)$, quando considerados os dados por esfera administrativa, no Grupo 1, só houve ascensão no número de matrículas totais efetivadas na rede municipal.

No Grupo 2, buscou-se apreender a cobertura da $2^{2}$ etapa do ensino fundamental em relação a $1^{\text {a. }}$. Para tanto, foram apresentados o total de matrículas e as matrículas de alunos com deficiência efetuadas na $4^{a}$ série/ $5^{0}$ ano do ensino fundamental, em 2007, e as matrículas totais e de alunos com deficiência, realizadas na $5^{\underline{a}}$ série/ $6^{\circ}$ ano do ensino fundamental, em 2008. Obtiveram-se os seguintes dados:

Gráfico 3 - Brasil: total de matrículas na $4^{\underline{a}}$ série/ $5^{\underline{o}}$ ano do Ensino Fundamental (2007) e na $5^{\text {a }}$ série/ $6^{\underline{0}}$ ano do Ensino Fundamental (2008)

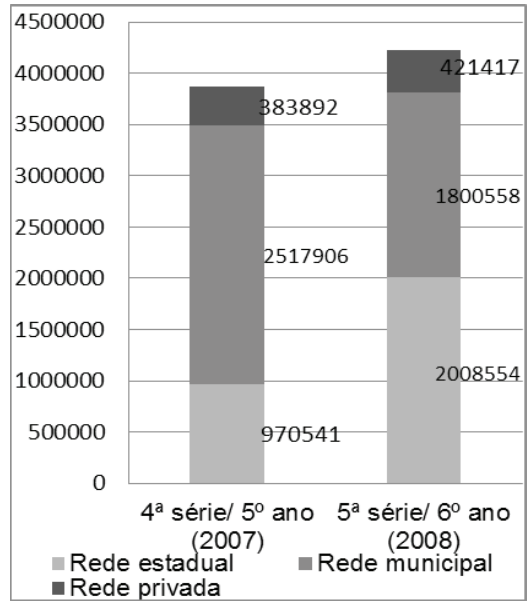

Revista Educação Especial | v. 27 | n. 49 | p. 283-298| maio/ago. 2014

Santa Maria 
Gráfico 4 - Brasil: matrículas de alunos com deficiência na $4^{a \underline{a}}$ série/ $5^{\circ}$ ano do Ensino Fundamental (2007) e na $5^{\mathrm{a}}$ série/ $6^{\mathrm{o}}$ ano do ensino fundamental (2008).

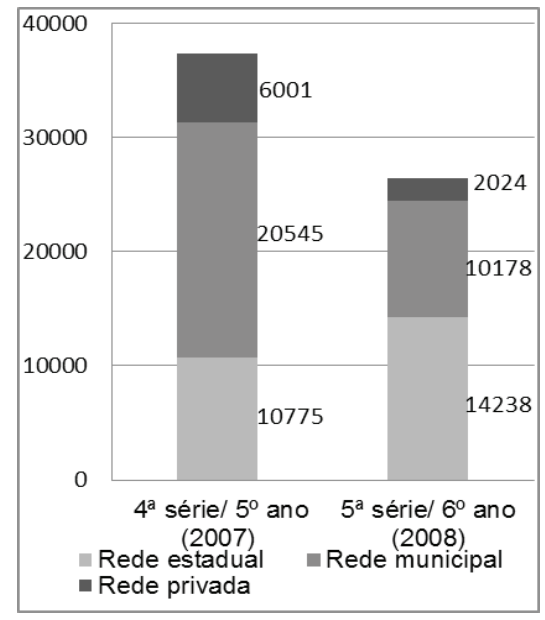

Está evidente que, enquanto houve crescimento no número de matrículas totais chegando a 9,30\%, o número de matrículas de alunos com deficiência diminuiu, configurando uma queda de 29,02\%.

Ao observar os dados por dependência administrativa, nota-se que o número de alunos com deficiência ampliou no âmbito estadual, apresentando um aumento de $32,13 \%$. Esse aumento se dá de forma mais notável quando se considera o número total de matrículas, atingindo $106,95 \%$. No que condiz ao âmbito municipal, as matrículas apresentadas nos gráficos 3 e 4 sofreram decréscimo. Novamente a queda foi maior nas matrículas de alunos com deficiência $(50,45 \%)$ que nas totais $(28,48 \%)$.

A redução de matrículas, no âmbito municipal, pode ter como plano de fundo a descentralização dos primeiros anos do ensino fundamental. Neste sentido, é preciso esclarecer que os munícipios têm se responsabilizado pelo provimento da educação infantil e da primeira etapa do ensino fundamental e os estados têm ficado responsáveis pelo provimento da segunda etapa do ensino fundamental e pelo ensino médio.

Quanto à esfera privada, percebe-se, novamente, uma perda bastante acentuada nas matrículas de alunos com deficiência, chegando a 66,27\%. Esse percentual, considerando-se as matrículas totais, ampliou 9,77\%.

Desse modo, os dados apresentados demonstram um movimento de ascensão nas matrículas totais, não sendo ampliadas somente as matrículas da rede municipal, que apresentaram declínio justificado. Já as matrículas efetuadas por alunos com deficiência sofreram redução nas redes municipal e particular e um aumento tênue na estadual.

No Grupo 3, buscou-se observar o quadro de continuidade nos estudos na $2^{\underline{a}}$ etapa do ensino fundamental ( $5^{\underline{a} a}$ série/ $6^{0}$ ano até $8^{a}$ série/ $9^{\circ}$ ano). Para tanto, apre- 
ciou-se o número total de matrículas e de alunos com deficiência efetivadas na $5^{\underline{a}}$ série/ $6^{0}$ ano, em 2007, em comparação com o número de matrículas totais e de alunos com deficiência realizadas na $8^{\underline{a}}$ série/ $9^{\underline{o}}$ ano, em 2010. Foram obtidos os seguintes dados:

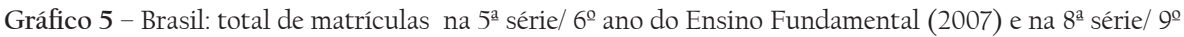
ano do Ensino Fundamental (2010).

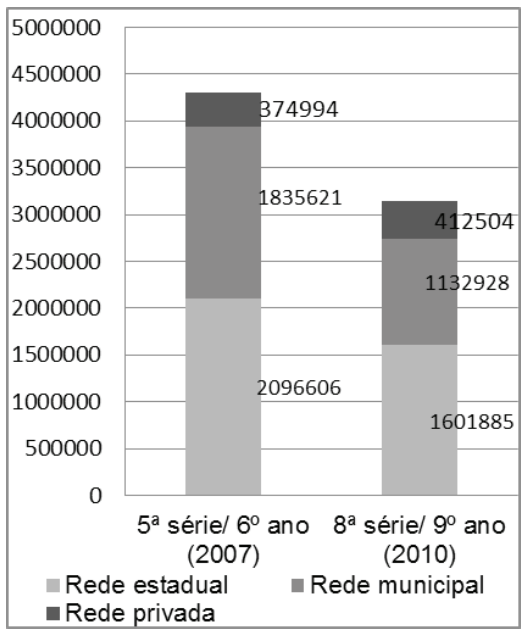

Gráfico 6 - Brasil: matrículas de alunos com deficiência na $5^{\underline{a}}$ série/ 6oano do Ensino Fundamental (2007) e na $8^{\underline{a}}$ série/ $9^{\underline{o}}$ ano do Ensino Fundamental (2010).

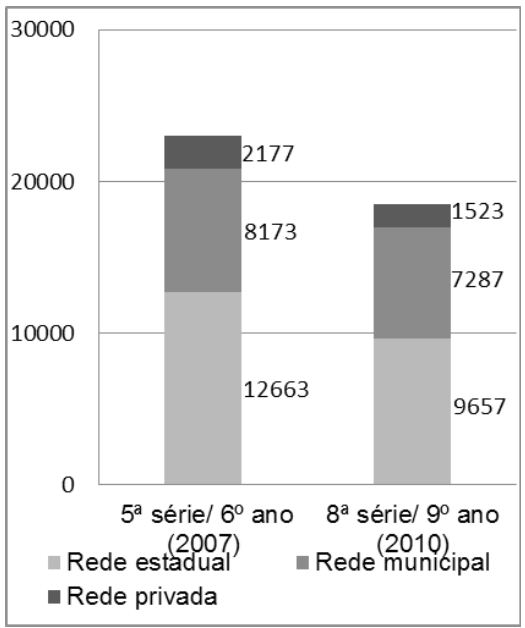

Tanto o total de matrículas quanto as matrículas de alunos com deficiência sofreram declínio. O decréscimo foi mais acentuado no número de matrículas totais $(26,88 \%)$ do que nas matrículas realizadas por alunos com deficiência (19,79\%). 
Quanto às esferas administrativas, nas dependências estadual e municipal, tanto o total de matrículas, quanto as de alunos com deficiência sofreram redução. Essa perda, no total de matrículas efetivadas na rede estadual, foi de $23,73 \%$, as matrículas de alunos com deficiência reduziram 23,59\%. No que se refere ao âmbito municipal, o decréscimo foi mais acentuado no total de matrículas, chegando a $38,28 \%$, sendo que as matrículas de alunos com deficiência sofrem queda mais tênue (10,84\%).

Nota-se que, na esfera privada, ocorreu uma redução de 30,04\% no tocante das matrículas de alunos com deficiência. Enquanto as matrículas totais aumentaram 10\% na mesma esfera. Deste modo, os dados do Grupo 3 demonstraram que, de modo geral, a queda foi mais tênue nas matrículas efetuadas por alunos com deficiência $(19,79 \%)$ que nas matrículas totais (26,88\%). Contudo, todas as esferas administrativas sofreram redução no número de matrículas de alunos com deficiência, enquanto a rede privada apresentou ascensão no número de total de matrículas.

No Grupo 4, buscou-se expor a cobertura do ensino médio em relação a última série/ ano do ensino fundamental. Para tanto, apresentou-se o número de matrículas totais e de alunos com deficiência efetivas na $8^{\text {a }}$ série/ $9^{\circ}$ ano do ensino fundamental, em 2007, em relação ao número total de matrículas e de alunos com deficiência, realizadas no $1^{\mathfrak{o}}$ ano do ensino médio, em 2008. Obtendo a seguinte configuração:

Gráfico 7 - Brasil: total de matrículas na 8ª série/ 9oano do Ensino Fundamental (2007) e no lō ano do Ensino Médio (2008).

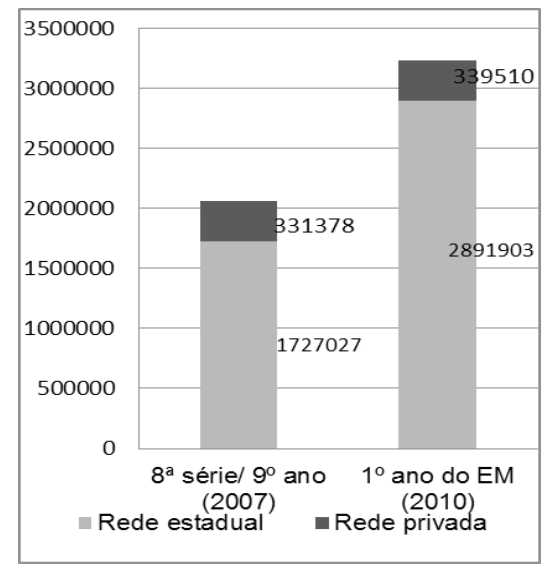


Gráfico 8 - Brasil: matrículas de alunos com deficiência na 8ª série/ 9o ano do Ensino Fundamental (2007) e no $\mathrm{l}^{\mathrm{o}}$ ano do Ensino Médio (2008).

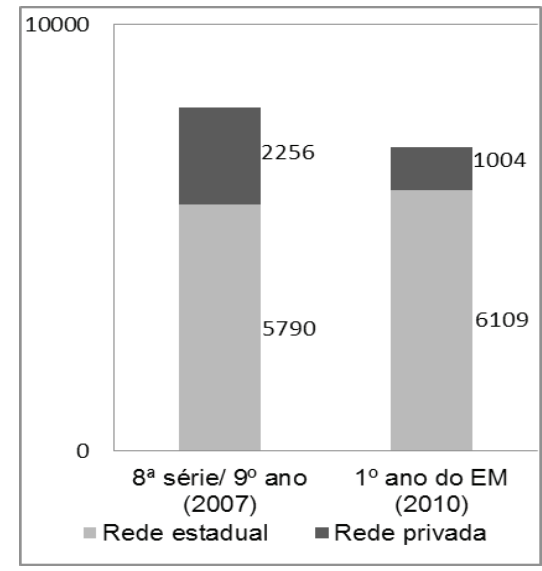

Nota-se que, enquanto há aumento de 8,19\% no número total de matrículas, as matrículas efetivadas por alunos com deficiência sofreram queda de 36,23\%. Demonstrando que, a cobertura de acesso no que condiz às matrículas gerais, tem sido "eficiente" no ensino médio, deixando a desejar no montante de matrículas efetivadas por alunos com deficiência. Sendo que é preciso considerar que as matrículas efetivadas no $1^{\mathfrak{Q}}$ ano do ensino médio, em 2010, não são, necessariamente, dos mesmos alunos que realizaram suas matrículas na 8ํㅗ́rie/ 9oano, em 2007.

As matrículas, no âmbito estadual, progrediram nos gráficos 7 e 8, apresentando um aumento mais acentuado $(67,44 \%)$, quando se trata do total de matrículas, e mais suave $(5,50 \%)$ ao se remeter às matrículas de alunos com deficiência. Na esfera privada, a queda foi acentuada, no que condiz às matrículas de alunos com deficiência (55,49\%). As matrículas totais, nessa esfera, ampliaram 2,45\%.

Desse modo, os dados desse grupo desvelaram uma queda bem mais acentuada no que se refere às matrículas de alunos com deficiência, esse movimento ocorreu de modo geral e por esferas administrativas.

Por fim, no Grupo 5, analisou-se o número de matrículas efetivadas no $1^{\circ}$ ano do ensino médio, em 2008, e no $3^{\circ}$ ano do ensino médio, em 2010, buscando-se visualizar a continuidade de acesso nessa etapa de ensino. Os seguintes dados foram obtidos: 
Gráfico 9 - Brasil: total de matrículas no $1^{\circ}$ ano do Ensino Médio (2008) e no 3o ano do Ensino Médio (2010).

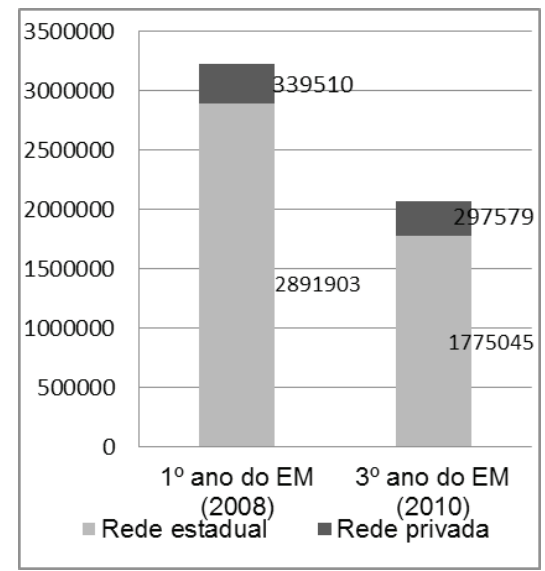

Gráfico 10 - Brasil: matrículas de alunos com deficiências no lo ano do Ensino Médio (2008) e no 3ํano do Ensino Médio (2010).

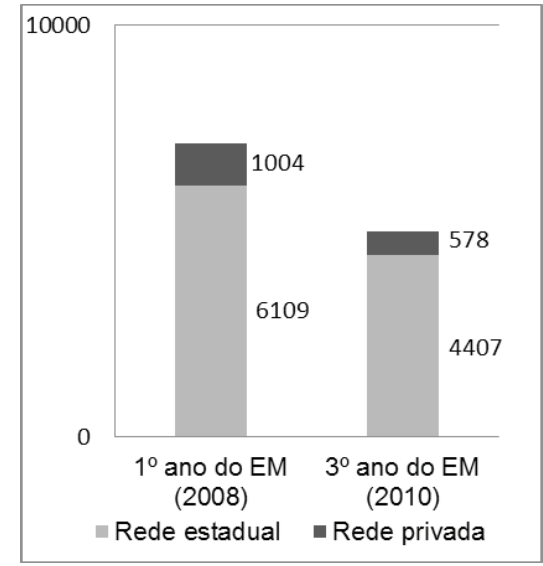

Houve considerável redução no número total de matrículas e nas de alunos com deficiência. No que tange às matrículas totais, a perda foi de 33,50\%, no número de matrículas efetivadas por alunos com deficiência o decréscimo foi um pouco menor: $29,75 \%$.

Quando considerados os dados por dependência administrativa, na esfera estadual, tanto o número total de matrículas quanto o número de matrículas de alunos com deficiência sofreram considerável perda, 38,62\% e 27,86\%, respectivamente. 
No setor privado, o decréscimo mais acentuado foi no número de matrículas efetivadas por alunos com deficiência (42,43\%), no total de matrículas também houve queda $(12,35 \%)$.

Nesse sentido, os dados revelaram que o número de matrículas de alunos com deficiência sofreu redução nas redes apresentadas e que o total de matrículas também sofreu perda acentuada nas esferas administrativas.

\section{Considerações finais}

As políticas direcionadas ao ensino médio e à educação especial, ao longo da história brasileira, tiveram marcas de descontinuidade que permeiam até hoje a conceituação/ concepção dessa etapa e modalidade de ensino.

Nesse sentido, o ensino médio esteve, historicamente, dividido entre oferecer uma educação profissional, com caráter de terminalidade, e/ou propedêutica, ou seja, voltada ao prosseguimento dos estudos. A educação especial, por sua vez, esteve muito próxima do âmbito filantrópico, condição que comprometeu seu caráter público.

Somente com a aprovação da CF/88, ocorreram avanços mais significativos, sendo outorgada a "progressiva extensão da obrigatoriedade e gratuidade do ensino médio" e a oferta de "atendimento educacional especializado aos portadores de deficiência preferencialmente na rede regular de ensino". Recentemente, em 2009, com EC no 59 outorgou-se a "gratuidade e obrigatoriedade" da educação básica.

O ensino médio, mesmo se tornando uma etapa da educação básica na LDB/96, careceu de uma conceituação/concepção mais delineada. A educação especial, em âmbito nacional, na LDB/96, foi conceituada como uma "modalidade de educação escolar" a ser ofertada "preferencialmente na rede regular de ensino". Abrindo-se precedente para que os apoios as instituição privadas, sem fins lucrativos, continuassem. Com a aprovação da Política Nacional de Educação Especial na Perspectiva da Educação Inclusiva (BRASIL, 2008a) a educação especial se configurou como uma modalidade de ensino complementar ou suplementar, não sendo substitutiva. Entende-se que essa política dispôs orientações que, somadas ao Decreto no 6.571 (2008b) e à Resolução no 4 (BRASIL, 2009a), pleitearam a educação pública para os alunos com NEE. Contudo, com a recente publicação do Decreto 7.61l (BRASIL, 201lb), retomouse o termo "preferencialmente", abrindo-se, novamente, precedente para que as instituições privadas continuassem a ofertar educação especial com caráter substitutivo.

Os dados analisados revelam que ocorreu uma redução de matrículas dos alunos que apresentam deficiência durante sua trajetória do ensino fundamental ao médio, havendo queda em todos os grupos de análise. A maior queda se deu no Grupo 1 que retratou, neste caso, a descontinuidade dos estudos de alunos com deficiência na primeira etapa do ensino fundamental. Nesse sentido, em números absolutos, enquanto, em 2007, registrou-se 134.536 matrículas de alunos com deficiência na $1^{a}$ série/ $2^{\underline{0}}$ ano do ensino fundamental, em 2010, registrou-se apenas 56.218 matrículas referentes à mesma demanda, apresentando, assim, um declive exorbitante de 58,22\%.

Revista Educação Especial | v. 27 | n. 49 | p. 283-298| maio/ago. 2014

Santa Maria 
Denota-se, que a esfera administrativa que mais "contribuiu" com essa redução foi a privada, pois, na mesma, havia 63.671 alunos com deficiência matriculados na $\mathbf{l}^{\mathrm{a}}$ série/ $2^{\mathrm{o}}$ ano do ensino fundamental, em 2007, e em 2010, registrou-se apenas 5.512 alunos com deficiência na $4^{\mathrm{a}}$ série/ $5^{\mathrm{o}}$ ano do ensino fundamental, configurando uma redução de $91,34 \%$.

É interessante notar que o número de alunos com deficiência matriculados na $1^{\underline{a}}$ série/2 $2^{\underline{0}}$ ano, em 2007, no setor privado, correspondia a 47,31\% do número de matrículas de alunos com deficiência nessa série/ ano. Sendo que as matrículas realizadas nas outras esferas correspondiam aos seguintes percentuais: federal 0,09\%; estadual $19,49 \%$ e municipal 33,09\%.

Ressalta-se que a esfera privada conta com um grande número de instituições sem fins lucrativos que atendem aos alunos com deficiência. $\mathrm{O}$ alto número de matrículas de alunos com deficiência na $1^{\underline{a}}$ série/ $2^{2}$ ano, em 2007 e, o declive no período analisado, podem indicar que esse contingente de alunos têm evadido ou ficado retido no início do ensino fundamental em escolas especiais.

Quando considerado o total de matrículas, há uma certa mudança de perspectiva, pois percebeu-se aumento no contingente de matrículas do Grupo 2, que retratou a cobertura da segunda etapa do ensino fundamental em relação a última série da primeira etapa do ensino fundamental; e no Grupo 4, que ilustrou a cobertura do ensino médio em relação a última série do ensino fundamental. Muito embora esteja contemplada a questão do acesso e da transversalidade da educação especial, sobretudo, na Constituição Federal (1988) e na Lei de Diretrizes e Bases da Educação Nacional (1996), a análise dos Microdados demonstra que poucos são os alunos com deficiência que chegam ao ensino médio.

Ainda, observou-se que o decréscimo mais acentuado nas matrículas totais ocorreu justamente no Grupo 5, ilustrando a descontinuidade nos estudos na terceira etapa da educação básica. Nesse sentido, de acordo com os dados, enquanto havia, em 2008 , 3.283.938 alunos matriculados no $1^{0}$ ano do ensino médio, em 2010, foram registradas 2.183.686 matrículas no $3^{\circ}$ ano do ensino médio, representando uma redução de $33,50 \%$.

Talvez isso se deva ao fato de o ensino médio não ter sua identidade bem delineada, pois de acordo com Nora Krawczyk (2008), é consensual entre os pesquisadores, que o ensino médio é a etapa de ensino que provoca os debates mais controversos na educação básica. A autora também explicita que as debilidades nessa etapa de ensino se devem, principalmente, à presença de um projeto de democratização tardia.

Ressalta-se, ainda, que as matrículas de alunos com deficiência, em relação ao total, diminuem conforme se analisa dados de etapas mais elevadas da educação básica, por isso o número de alunos que chega a ter acesso ao ensino médio é tão ínfimo.

Assim, o percentual de matrículas de alunos com deficiência em relação ao

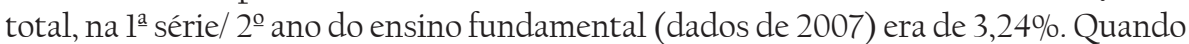
se analisa dados referentes a $4^{a}$ série/ $5^{\circ}$ ano do ensino fundamental (dados de 2007 e 2010) esse percentual diminui para 1,29\%. Na $5^{a}$ série/ $6^{\circ}$ ano (dados de 2007 e 2008) 
há mais redução, sendo que a porcentagem chega à 0,58\%. Na $8^{a}$ série/ $9^{0}$ ano (dados de 2007 e 2010), o percentual de matrículas de alunos com deficiência em relação ao número total de matrículas é menor, chegando a $0,48 \%$. No $1^{\circ}$ ano do ensino médio (2008), há mais redução, chegando a um percentual ínfimo de $0,22 \%$. No $3^{\circ}$ ano do ensino médio (2010), há um pequeno aumento, chegando a $0,24 \%$.

Os cenários, aqui analisados, revelam a necessidade do poder público em primar pela garantia de fato ao direito ao ensino médio os alunos que possuem deficiência pela via da elaboração de políticas públicas que articulem a inclusão educacional para além da "inclusão concedida".

\section{Referências}

BARROS, W. M. B. O trabalho Pedagógico no EM, na rede pública estadual paulista: desafios à inclusão dos alunos com deficiência. 230 f. Dissertação (Mestrado em Educação). Pontifícia Universidade Católica de Campinas. Campinas, 2008. Disponível em: 〈http://www.bibliotecadigital.puc-campinas.edu. br/tde_busca/arquivo.php?codArquivo=441). Acesso em: 18 fev. 2013.

BRASIL. Constituição da República Federativa do Brasil de 1988. Casa Civil; Subchefia para Assuntos Jurídicos, Brasília, DF, 05 out. 1988. Disponível em 〈http://www.planalto.gov.br/ccivil_03/constituicao/ constitui\%C3\%A7ao.htm>. Acesso em: 28 dez. 2011.

. Lei no 9.394 de 20 de dezembro de 1996. Estabelece as diretrizes e bases da educação nacional. Casa Civil; Subchefia para Assuntos Jurídicos, Brasília, DF, 20 dez. 1996. Disponível em 〈http://www.planalto. gov.br/ccivil_03/Leis/L9394.htm>. Acesso em: 28 nov. 2011.

. Lei no 11.274, de 6 de fevereiro de 2006. Casa Civil; Subchefia para Assuntos Jurídicos, Brasília, DF, fevereiro, 2006. Disponível em: 〈http://www.planalto.gov.br/ccivil_03/_Ato2004-2006/2006/Lei/L11274. htm. Acesso em: 09 jan. 2012.

Ministério da Educação. Instituto Nacional de Estudos e Pesquisas Educacionais Anísio Teixeira. Microdados do Censo Escolar 2007. Brasília, DF, 2007. Disponível em: ‘http://portal.inep.gov.br/basica-levantamentos-acessar>. Acesso em: 21 dez. 2011.

. Emenda Constitucional no 59, de 11 de novembro de 2009. Casa Civil; Subchefia para Assuntos Jurídicos, Brasília, DF, 11 nov. 2009. Disponível em: < http://www.planalto.gov.br/ccivil_03/constituicao/ emendas/emc/emc59.htm>. Acesso em 01 jun. 2011

CARVALHO, A. P. de. Políticas de educação especial no ensino médio público paranaense: o aluno com deficiência em foco. 200f. Dissertação (Mestrado em Educação). Universidade Federal do Paraná. Curitiba, 2012. Disponível em: 〈http://dspace.c3sl.ufpr.br/dspace/bitstream/handle/1884/27815/R\%20-\%20 D\%20-\%20CARVALHO,\%20ANA\%20PAULA.pdf?sequence=1〉. Acesso em: 06 fev. 2013.

CAVALCANTI, A. M. L. A inclusão do aluno com deficiência mental no ensino médio: um estudo de caso. 158 f. Dissertação (Mestrado em Educação). Universidade Federal do Rio Grande do Norte. Natal, 2007. Disponível em: 〈http://bdtd.bczm.ufrn.br/tedesimplificado//tde_busca/arquivo.php?codArquivo=1529.. Acesso em: 13 dez. 2012.

CRUZ, R. A. S. da. Ensino médio no estado de São Paulo: desafios na escolarização de alunos com deficiência. 2llf. Dissertação (Mestrado em Educação e Ciências Humanas). Universidade Federal de São Carlos, São Carlos, SP, 2011. Disponível em: 〈http://200.136.241.56/htdocs/tedeSimplificado/tde_busca/ arquivo.php?codArquivo=4328>. Acesso em: 05 fev. 2013.

DIAS, S. de S. O sujeito por trás do rótulo: significações de si em narrativas de estudantes de ensino médio com indicação de deficiência mental. 209 f. Dissertação (Mestrado em Psicologia). Universidade de Brasília, Brasília, 2004.

IBGE - INSTITUTO BRASILEIRO DE GEOGRAFIA E ESTATÍSTICA. Censo Demográfico 2010: características gerais da população, religião e pessoas com deficiência. Disponível em 〈http://www.ibge.gov. br/home/estatistica/populacao/censo2010/caracteristicas_religiao_deficiencia/caracteristicas_religiao_deficiencia_tab_pdf.shtm>. Acesso em: 19 out. 2012. 
KRAWCZYK, N. Balanço e perspectivas do ensino médio no Brasil. Ceará, Out. 2008. Palestra proferida pela profa. Nora Krawczyk na Audiência Publica realizada em agosto de 2007, pela Secretaria Estadual de Educação do Ceará, por ocasião da elaboração do Plano Decenal do Estado.

MOREIRA, L. C.; TAVARES, T. M. O aluno com necessidades educacionais especiais do ensino médio no Município de Curitiba: indicativos iniciais para as políticas públicas. In: BAPTISTA, C. R.; JESUS, D. M. Avanços em políticas de inclusão: o contexto da educação especial no Brasil e em outros países. Porto Alegre: Mediação, 2009.

PINTO, J. M. R.; ALVES, T. O impacto financeiro da ampliação da obrigatoriedade escolar no contexto do Fundeb. Educação \& Realidade, Porto alegre, v. 36, n. 2, p. 605-624, mais/ago. 2011. Disponível em: ‘http:// seer.ufrgs.br/educacaoerealidade/article/view/15128/12931>. Acesso em: 07 dez. 2012.

SUDRÉ, E. C. O ensino-aprendizagem de alunos Surdos no Ensino Médio em classe de ensino regular. 198 f. Dissertação (Mestrado em Linguística Aplicada e Estudos da Linguagem), Pontifícia Universidade Católica de São Paulo, São Paulo, 2008. Disponível em: 〈http://www.sapientia.pucsp.br//tde_busca/arquivo.php?codarquivo=8234>. Acesso em: 01 maio 2012.

\section{Notas}

${ }^{1}$ As deficiências contempladas pelo Censo Demográfico, de 2010, foram: deficiência visual, auditiva e motora, subdivididas em: não consegue de modo algum, grande dificuldade e alguma dificuldade e deficiência mental/ intelectual.

${ }^{2}$ Disponivel em: 〈http://www-0l.ibm.com/software/analytics/spss/>

${ }^{3}$ Para computar os dados, referentes ao ensino fundamental, tendo em vista a Lei $n^{\varrho} 11.274$ (BRASIL, 2006) que garantiu a duração de nove anos para o ensino fundamental, foram somadas as matrículas da $1^{a}$ série do ensino fundamental de oito anos (que ainda estava em vigência em muitos estados) com as matrículas do $2^{\circ}$ ano do ensino fundamental de nove anos (no qual os alunos têm idade correspondente à $1^{\mathrm{a}}$ série do ensino fundamental de oito anos. Além disso, em todos os grupos foram contabilizadas o número de matrículas total e de alunos com deficiência.

${ }^{4}$ Fonte dos dados: Microdados MEC/ Inep, disponíveis para download em: < http://portal.inep.gov.br/basicalevantamentos-acessar`. Utilizou-se a mesma fonte para a formulação de todos os gráficos.

${ }^{5}$ Foram contabilizadas, inclusive, as matrículas realizadas no âmbito federal. Ao apresentar a ascensão/ queda das matrículas no total, procedeu-se, em todos os grupos de análise, considerando-se, inclusive, as matrículas das redes que foram desconsideradas nos gráficos (por abrangerem menos que 5\% das matrículas).

\section{Correspondência}

Laura Ceretta Moreira - Universidade Federal do Paraná, Setor de Educação, Departamento de Planejamento de Administração Escolar. Rua General Carneiro, 460, Centro, CEP: 80060-150 - Curitiba, Paraná - Brasil.

E-mail:laurac.moreira@gmail.com

Recebido em 11 de junho de 2013

Aprovado em 14 de outubro de 2013 